\title{
LINGUÍSTICA, PSICANÁLISE, EDUCAÇÃO E OS FALANTES DE UMA LÍNGUA DE SINAIS
}

\author{
Cristóvão Giovani Burgarelli (UFG)* \\ https://orcid.org/0000-0002-1060-0005
}

\section{RESUMO}

Tomando como aporte teórico tanto o reconhecimento quanto a subversão a que Lacan promove a linguística saussureana, tomarei como objetivo, neste artigo, introduzir algumas questões que considero pertinentes para pensar a educação dos falantes de uma língua de sinais. Para dialogar com a linguística, vou dar atenção especial às elaborações de Jean-Claude Milner, em seu livro $O$ amor $d a$ língua, e, para a questão mais específica da língua de sinais, vou recorrer ao livro Des mains pour parler, des yeux pour entendre: la voix et les enfants Sourds, de André Meynard. Proponho que, para avançar com as questões aqui apresentadas, deve-se privilegiar a elaboração lacaniana em torno de uma teoria da escrita, sinalizando para a afirmação de que a experiência educativa com os falantes de Libras não pode deixar de interrogar-se a respeito das condições de fala dos educandos nela envolvidos.

Palavras-chave: Linguística. Psicanálise. Língua de sinais. Experiência educativa.

\section{ABSTRACT}

\section{LINGUISTICS, PSYCHOANALYSIS, EDUCATION AND THE SIGN LANGUAGE SPEAKERS}

Assuming as theoretical contribution the recognition and subversion to which Lacan promotes the linguistics of Ferdinand de Saussure, the goal of this article is to introduce some questions that I consider pertinent to think about the education of the speakers of a sign language. In dialogue with linguistics, I will pay special attention to the elaborations of Jean-Claude Milner, in his book For the love of language, and for the most specific question of sign language I will turn to the book Des mains pour parler, des yeux pour entendre: la voix et les enfants Sourds, by André Maynard. I propose that, in order to move forward with the questions presented here, one should focus on Lacanian elaboration around a theory of writing, signaling to the assertion that the educational experience

* Pós-doutorado em Ciências da Educação pela Universidade Paris 8, Vincennes-Saint-Denis. Doutor em Linguística pela Universidade Estadual de Campinas (Unicamp). Psicanalista. Professor titular da Faculdade de Educação e do Programa de Pós-graduação em Psicologia da Universidade Federal de Goiás (UFG). Coordenador do Grupo de Estudos, Pesquisa e Extensão dos Fundamentos Litorais entre Linguagem, Psicanálise e Educação (Entraste/UFG) e membro do Grupo Centro de Pesquisa: Psicanálise entre Ciência e Arte (Outrarte/Unicamp). Membro do Grupo de Trabalho Psicanálise e Educação da Associação Nacional de Pesquisa e Pós-Graduação em Psicologia (ANPEPP). E-mail: crgiovani@gmail.com 
with the speakers of LIBRAS (Brazilian Sign Language) can not refrain from questioning the speaking conditions of the students involved in it.

Keywords: Linguistics. Psychoanalysis. Sign language. Educational experience.

\section{RESUMEM \\ LINGÜÍSTICA, PSICOANÁLISIS, EDUCACIÓN Y LOS HABLANTES DE UNA LENGUA DE SEÑALES}

Tomando como aporte teórico tanto el reconocimiento como la subversión a que Lacan promueve la lingüística saussureana, tomaré como objetivo, en este artículo, introducir algunas cuestiones que considero pertinentes para pensar la educación de los hablantes de una lengua de señales. Para dialogar con la linguística, daré atención especial a las elaboraciones de Jean-Claude Milner, en su libro $O$ amor da língua, y, para la cuestión más específica de la lengua de señales, recurriré al libro Des mains pour parler, des yeux pour entendre: la voix et les enfants Sourds, de André Meynard. Propongo que, para avanzar con las cuestiones aquí presentadas, se debe privilegiar la elaboración lacaniana en torno de una teoría de la escritura, apuntando hacia la afirmación de que la experiencia educativa con los hablantes de la Lengua Brasileña de Señales LIBRAS no puede dejar de interrogarse a sí misma acerca de las condiciones de habla de los educandos en ella implicados.

Palabras clave: Linguística. Psicoanálisis. Lengua de señales. Experiencia educativa.

\section{Introdução}

Embora boba, a pergunta "de qual linguística estou falando?" parece-me muito importante. Tentarei responder a ela no decorrer desta minha elaboração, porém adianto aqui algumas pinceladas, que poderão servir de orientação ao leitor. 0 ponto principal é mesmo considerar que Saussure (2006), no Curso de linguística geral, pratica o gesto de autoria que inaugura uma nova ciência, sendo que nova aqui quer dizer que ele põe em questão tanto as bases da filosofia clássica quanto as de toda uma tradição em torno da concepção de signo. Língua não será mais, portanto, representação (nem de um mundo natural nem de um saber unívoco, nem das ideias ou pensamentos de um eu, em sua univocidade). Não será mais, também, nomenclatura, que estabeleceria uma relação biunívoca entre um nome e uma coisa (ou ideia). Trata-se, então, ainda, de uma guinada com relação à psicologia, que acabava de nascer como ciência, pois, em sua ordem própria, a língua não mais será instrumento para ajudar a agir, pensar ou interagir, mas sim uma instância (histórica) em que tais fazeres humanos se fundam.

Nessa mesma linha de raciocínio cabe também perguntar “o que é a psicanálise?”, ou seja, uma vez que existe o inconsciente freudiano, como fica a dinâmica da língua estabelecida por Saussure como um sistema de signos em que a combinação entre significado e significante - embora puramente diferenciais se tomados em separado - constitui-se como "uma coisa [fato] positiva em sua ordem" (Saussure, 2006, p. 139)? Se Freud, guiado por questões outras, se aventurou a escrever o aparelho psíquico a partir da instância "signos de percepção" (Wahrnehmungszeichen), para marcar a sua concepção de uma memória inconsciente, com traços a serem retomados num só depois, Saussure pôde, por sua vez - e isso porque contou com "devoção de alguns seus discípulos" 
(Lacan, 1998a, p. 500) -, estabelecer a língua como objeto e fundar a linguística com o estatuto de uma ciência. Contudo, "o que é a língua se a psicanálise existe?" O modo como Milner (2012) desenvolve essa pergunta ajuda-nos, sem dúvida, a entender essa discussão, principalmente quando nos diz que o método advindo do próprio conceito de inconsciente não pode ser outro senão partir do que comparece como resto, ou desvio, no que pôde advir como constituído, assimilável ou, nos seus próprios termos, calculável por e para uma ciência.

Para nosso terceiro passo, a pergunta mais importante talvez seja "o que os falantes de uma língua de sinais podem nos ensinar a respeito da inter-relação entre linguística, psicanálise e educação aqui proposta?" Para desenvolvê-la, tomarei como exemplo a elaboração de Meynard (2016), no livro Des mains pour parler, des yeux pour entendre: la voix et les enfants Sourds (Mãos para falar, olhos para ouvir: a voz e as crianças Surdas). Nesse trabalho, esse autor, a partir de um conhecimento aprofundado tanto da Língua de Sinais Francesa (LSF) quanto do sistema político-jurídico-medical da França, contrapõe-se radicalmente aos discursos oficiais cuja tônica é antecipar, na infância, o diagnóstico de surdez ${ }^{1}$ e tratar os surdos como deficientes. Além disso, embasado tanto no estabelecimento pela linguística de que a língua de sinais é uma língua, quanto na descoberta freudiana, a do inconsciente, Meynard (2016) nos convoca ao reconhecimento da condição de falantes dessas crianças; um reconhecimento que pode levá-las a tomar a palavra na Língua Francesa de Sinais e, portanto, habitar tanto o campo da linguagem quanto o das formações do inconsciente.

Com esse percurso, pretendo, por fim, trazer alguns desdobramentos que considero pertinentes e fundamentais a uma prática educativa com os denominados surdos, que

1 Conforme Meynard (2016), trata-se de uma doença no âmbito da saúde pública, inventada pelos expertos da Alta Autoridade de Saúde (Haute Autorité de Santé - HAS), a qual se chama Surdez Permanente Neonatal (Surdité Permanente Néonatal - SPN), e deve ser diagnosticada no segundo dia de vida. eu prefiro denominar, no nosso caso, como falantes de Libras. Para tal, buscarei situar-me diante das discussões que venho travando na minha experiência como professor no âmbito de uma Faculdade de Educação e, mais especificamente, no curso de Pedagogia, cujo projeto tem como objetivo principal "a formação de professores para o magistério da Educação Infantil e dos Anos Iniciais do Ensino Fundamental" (UNIVERSIDADE FEDERAL DE GOIÁS, 2015). Quanto a isso, é importante frisar a função da área da linguagem na abrangência dessa proposta educacional, pois os vários anos de ensino, pesquisa e extensão, desenvolvidos a partir desse lugar, ensinaram-me, sobretudo, a importância de fundamentos mais radicais (o que quer dizer retirados da própria área) para abordar os seus diversos componentes - educação infantil, alfabetização, ensino de Língua Portuguesa, Libras, a relação entre linguagem e inclusão, linguagem e educação especial, educação de adultos, patologias, entre outros - primeiramente como uma questão subjetiva e dependente de um encadeamento linguístico-discursivo.

\section{0 que aprender com a linguística?}

Vou dar meu pimeiro passo, portanto, com a linguística, e, como eu disse, vou recorrer ao percurso teórico-prático que venho trilhando; percurso iniciado, propriamente, em 1995, quando coincidem a minha entrada, pouco tempo após eu ter concluído o mestrado em Letras e Linguística, para a área de linguagem de um curso de Pedagogia e a defesa da tese $O$ quebra-cabeça: a instância da letra na aquisição da escrita (MOTA, 1995), de Sonia Borges, ${ }^{2}$ no doutorado em psicologia da educação da Pontifícia Universidade Católica de São Paulo (PUC-SP), sob a orientação de Cláudia Lemos. Não só ironias fazem parte do destino, mas também oximoros. Creio que este seja um.

2 Como houve mudança no nome dessa autora, nas referências finais deste artigo dirigir-se a Mota (1995). 
Uma tese defendida num programa de pósgraduação em Psicologia da Educação, mas com todas as coordenadas para consolidar-se como o marco inicial, no âmbito da aquisição da linguagem escrita e da alfabetização, de uma abordagem radicalmente contrária à Psicologia da Educação.

Recorrendo a vários textos de Cláudia Lemos, entre eles Sobre a aquisição de linguagem e seu dilema (pecado) original (DE Lemos, 1982), Borges (2006) discute - desde o início de seu trabalho, e posteriormente buscando haver-se com as consequências - o erro de tomar como ponto de partida a possível conciliação de compromissos entre a Psicologia, a Linguística e os dados empíricos ${ }^{3}$ referentes à aquisição da linguagem (oral e escrita). Ela diz: "o mencionado compromisso obriga a maioria dos investigadores a considerar a relação da criança com a linguagem como conhecimento e a descrever as transformações qualitativas em sua linguagem em termos de categorias e de estruturas definidas a partir da linguagem do adulto" (Borges, 2006, p. 36). ${ }^{4}$ Disso resulta uma consequência gravíssima: conforme Borges e Lemos, essa cegueira para o dado impossibilita "aos estudiosos da área de Educação de entender as peculiaridades da fala da criança em constituição" (Borges, 2006, p. 36).

Eis o ponto principal para a nossa questão aqui. Fundamentalmente, De Lemos (1982), do ponto de vista da linguística, ensina-nos a não "projetar teorias construídas a partir da análise de objetos - homogeneizados e abstraídos de sua relação com o sujeito - sobre a atividade linguística desse mesmo sujeito" (DE LEMOS, 1982, p. 120). 0 desafio proposto, portanto, é tomar como objeto de estudo a linguagem, "enfrentando assim a indeterminação, a mudança e a heterogeneidade desse objeto que se refaz a cada instância de seu uso" (DE LEMOS, 1982, p. 120). Diferentemente do que fazem a psicolinguística, a sociolinguística e a linguística apli-

3 Nesse caso, essa acepção não tem a ver com o empirismo, e sim com o inédito a que pode nos remeter uma experiência.

4 Basicamente, a tese de 1995 foi publicada neste livro: $O$ quebra-cabeça: a alfabetização depois de Lacan. cada, trata-se não de transpor para esse campo o sujeito psicológico ou, em outras palavras, o sujeito consciente, senhor de suas representações, mas sim de dar lugar ao falante, que se constitui, se forma, devido à sua inserção na própria experiência da fala. É, portanto, considerando o conceito de língua tal como fundado por Saussure, ou seja, pensando-a como uma materialidade significante que, ao ser encadeada, determina significados e valores, que é possível perguntar pelos efeitos formativos, constitutivos, nos atos discursivos concretos de um falante nos seus diversos momentos de relação com uma língua determinada.

Nesse sentido, o reconhecimento de que uma língua em seu conjunto estrutural precede, historicamente, ao falante e às suas capacidades intelectivas (que vão permitir a posteriori um certo saber sobre essa língua e sobre o seu uso), impede que o linguista e, por que não dizer, o educador embasado numa teoria da linguagem transponham para o campo de suas experiência a noção de um falante ideal, que já saberia, naturalmente, dirigir-se a tal objeto e utilizá-lo como meio de expressão e comunicação. Estou falando aqui, então, de uma concepção de linguagem da qual as instituições escolares podem lançar mão, tanto para teorizar quanto para praticar com a criança, ou outros aprendizes, a sua entrada, ou o seu aprimoramento, na fala, na leitura e na escrita.

Especificamente quanto ao fato de que as línguas de sinais são línguas, faz-se necessário considerar, como De Lemos (1982) nos ensina, que a produção inicial de alguém que está constituindo-se falante nessa língua (e por causa dela) é feita mesmo a partir de fragmentos combinados e recombinados, articulados, de um modo que geralmente vão comparecer para o adulto como indeterminados, se comparados com a língua instituída. Já com Borges (2006), podemos presumir que, se tais articulações seguem as leis de um funcionamento linguístico que dizem respeito tanto à oralidade quanto à escrita, então falar, ouvir, ler e escrever põem-se, primeiramente, na dependência de 
uma experiência que decorre da imersão do aprendiz, infans, no jogo que se abre, como um quebra-cabeça, a partir de tais leis. Imersão, portanto, no jogo dos significantes e das letras encadeadas. Contudo, o que seria o significante no caso de uma língua de sinais? Como na língua portuguesa, ou qualquer outra, cada traço distintivo em sua unicidade. E o que seria a letra? Igualmente, como nas demais línguas, cada suporte ali estruturalmente localizado que permitirá o enganchamento de outras letras, devido ao apagamento dos traços que permitiram fundar o significante em sua pura diferença.

À frente, pretendo explicitar melhor como isso pode ocorrer quando se trata de falar com as mãos e ouvir com os olhos, mas adianto que, a meu ver, é nesse ponto que culmina a confirmação da não-complementariedade entre Saussure e Lacan, a qual pudesse, talvez, fazer da psicanálise uma linguística aprimorada. Não mesmo, pois aqui já se encontram passagens teóricas importantes (subversões), como, por exemplo, as noções de significante, de letra, de sujeito e de objeto, que são basicamente os elementos de uma teoria da escrita em Lacan (principalmente em seu seminário A identificação (LACAN, 2020), de 1961-1962), que se constitui, sem dúvida, numa (re)formulação que se desloca, definitivamente, do edifício saussureano.

\section{0 que aprender com a Psicanálise?}

Neste segundo passo, acredito que, primeiramente, devo esclarecer por que, neste texto, eu inverto a ordem dos acontecimentos, colocando a linguística antes da psicanálise. É por causa de Lacan, que promoveu o retorno a Saussure para livrar a letra de Freud dos reducionismos, principalmente aqueles tributários a uma psicologia do eu. É por causa também de Cláudia Lemos, que, na sequência de seu texto acima mencionado, principalmente em Los processos metafóricos e metonímicos como me- canismos de câmbio (DE LEMOS, 1992), lançou mão do seguinte procedimento: semelhante ao propósito de Lacan, de retornar a Saussure para avançar com a Psicanálise, é importante retornar a Freud e a Lacan para avançar com as questões da linguística. Vale também a pena recordar, nesse momento, um debate que esteve muito presente no meio acadêmico nos anos de 1990, qual seja, aquele que indagava se Freud seria um linguista, o qual sinalizou, no mínimo, para o fato de que o aparelho psíquico pensado por Freud é, ao mesmo tempo, um aparelho de linguagem: "a tese de que a memória não se faz presente de uma só vez, mas se desdobra em vários tempos; [de] que ela é registrada em diferentes espécies de indicação" (FREUD, 1977, p. 317).

Não foi à toa que mencionei acima, na introdução, a pergunta a partir da qual Milner desenvolve, em 1978, o seu livro $O$ amor $d a$ língua (MILNER, 2012), que teve sua primeira publicação no Brasil em 1987, no qual a articulação entre linguística e psicanálise toma como passo fundamental a consideração tanto do que é uma língua para a linguística, quanto das consequências para uma reflexão sobre língua e linguagem a partir da descoberta freudiana do inconsciente. Conforme a sua elaboração, trata-se de interrogar pela possibilidade não só de reter do ser falante o que concerne a um objeto material, cuja substância (fônica, sintática, lexical etc.) pode ser descrita, mas também de pensar os desdobramentos de que, ao ser habitada por quem fala, a linguagem constitui o campo onde se articula gozo e sexualidade. Ali ele nos diz que, se por um lado a linguística escolheu perpetuar um instante instável e, por isso, permanecer na posição de descrever uma língua, por outro, Lacan forjou o termo lalíngua (lalangue), por considerar que, na estrutura da fala, está em jogo a dimensão do gozo. ${ }^{5}$

5 Pode ser importante mencionar aqui, pelo menos, duas das intervenções que esta minha elaboração recebeu dos pareceristas que avaliaram publicá-la ou não neste periódico, quais sejam, a necessidade de recorrer à Análise do Discurso para me livrar da "ideia bastante equivocada dos campos da linguística e da psicologia", ou ainda a sugestão de sanar tais equívocos com a leitura de outras publica- 
Moraes (1999) pode ajudar a desenvolver melhor essa consideração no ponto em que ela interessa às proposições que estou tentando articular aqui a respeito do estatuto de uma língua de sinais (Libras, por exemplo) na sua relação com uma outra língua (português, por exemplo). Essa autora nos esclarece sobre o fato de que, mesmo numa língua considerada materna, esse conceito de língua não nos diz outra coisa senão que habitar uma língua, ou seja, constituir-se nela, significa tomá-la como "o lugar ilusório da certeza do Eu", ao mesmo tempo em que representa a possibilidade da intervenção dos elementos da linguagem inconsciente, "daquilo que fala no Eu, sem seu consentimento" (MORAES, 1999, p. 6). Segundo essa autora, interrogar o familiar da língua materna e a suposta alteridade atribuída à língua estrangeira significa pensar as consequências do conceito de língua, pois, para além de um trabalho descritivo, outra coisa é tomar as diferenças entre duas línguas (supostamente materna ou estrangeira) a partir da relação entre falante e língua, relação que precisa ser abordada do ponto de vista do desconhecimento e estranhamento. Nesse sentido, falar é estar entre sistemas de linguagem, e a língua estrangeira não é "outra”, e sim aquela que lê a língua materna. Portanto, uma questão importante, para Moraes (1999), é pensar, a partir de Freud, como a linguagem separa a fala do corpo.

Sendo um campo complexo de associações de representações cujos efeitos se manifestam na fala (no sintoma, no sonho), a linguagem deixa de ser feita para designar as coisas, para se presentificar, sobretudo, como aquilo que separa o falante de si próprio. Se a linguagem representa, para Freud, o campo do desconhecimento, só podemos saber do que não sabemos, se falar-

ções recentes, como a História concisa da linguística, de Barbara Weedwood (2012), e os três livros de Introdução à linguística organizados por Mussalim e Bentes (2001a, 2001b, 2011). Na minha revisão para esta última proposta, tais intervenções muito me fizeram estudar e pensar. No entanto, mudar de trilha, com elas, seria perder o ponto definido aqui como axial, isto é, a própria equivocação que, conforme abordada pelos autores com os quais privilegiei discutir, aponta para a problemática das pulsões, freudianas, retomadas por Lacan a partir de suas proposições sobre o gozo. mos. Quando separa representação-palavra de associações de objeto, Freud está nos abrindo a possibilidade de não procurarmos as explicações em um só lugar. 0 fato de as associações de objeto (registradas no inconsciente) só encontrarem uma significação ao se ligarem a uma representação verbal (do pré-consciente) coloca a fala entre-sistemas de linguagem, pois as manifestações (inconscientes) de linguagem encontram, na fala, uma das possibilidades de mostrar seus movimentos. (MORAES, 1999, p. 51)

Os desdobramentos dessa abordagem permitem-nos pensar que o inconsciente se efetua no ser falante no campo da linguagem. Sendo assim, uma corporeidade não é natural, e sim concebida a partir dos efeitos da linguagem inconsciente. Moraes (1999) nos ajuda, então, a pensar o inconsciente como um aparelho psíquico, que também pode ser chamado de aparelho de memória, no qual, pelo efeito da linguagem, se escreve a pulsão. Portanto, cernir os enunciados de uma língua como "representáveis" implica marcar um limite no campo da enunciação. Como nos ensina Lacan (1998a), em A instância da letra no inconsciente, implica supor que o significante passou ao patamar do significado, deixando sobre a barra os efeitos que advêm das manifestações inconscientes irrepresentáveis, ou seja, deixando fora da conta a dimensão de gozo do significante, substância "opaca”, que não compõe, de fato, a "máquina formal", mas que é responsável por manter o circuito pulsional constante, causa fundadora de um corpo falante.

A partir de agora, creio que esteja claro o argumento com que terminei o item anterior dizendo sobre a necessidade desse passo teórico fundamental de Saussure a Lacan, ou seja: há um problema mal resolvido em Saussure com o qual precisamos avançar a partir de Lacan - o de que, "uma vez que o significante é apreendido como constituinte do signo, não há esperança de querer atingir sua dinâmica própria" (LE GAUFEY, 2018, p. 209). A visada de Lacan, portanto, precisará levar em consideração não só um retorno a Freud, principalmente 
à fenda que ele abre no edifício do "sujeito clássico, detentor e provedor de unidade" (LE GOUFEY, 2018, p. 13), ao proferir e perseguir a sua estranha proposição de que há representações inconscientes, mas também um retorno à tradição filosófica quanto à questão do signo em relação ao mundo e aos falantes. A ele será, portanto, necessário (des)ler, não sem Freud, tanto o tempo-chave do cogito cartesiano quanto "a articulação interna do patamar significante [...] fora do signo" (LE GAUFEY, 2018, p. 13), o que não permitiu a Saussure pensar a língua senão como um fato positivo, ou seja, como uma combinação "arbitrária" entre significado e significante (BURGARELLI, 2020).

\section{0 que aprender com os falantes de uma língua de sinais?}

Nesta parte do trabalho, considerando a questão apresentada desde o título, vou trazer, com base em Meynard (2016), um pouco da história sobre como os fundamentos da psicanálise puderam contribuir para o reconhecimento das línguas de sinais, tomando como exemplo a Língua Francesa de Sinais (LSF) e, na sequência, mostrar como uma experiência analítica com falantes de línguas de sinais pode fazer avançar esses próprios fundamentos. Também tentarei pensar, a partir desse contexto, algumas questões importantes ao que interessa neste momento específico de minha pesquisa, qual seja a articulação entre linguística, psicanálise e educação, principalmente no que diz respeito a uma prática educativa com os falantes da Língua Brasileira de Sinais (Libras), sem excluir dessa experiência o sujeito do inconsciente. Tentarei marcar que esse sujeito deverá ser concebido como efeito da operação inconsciente, cuja estrutura, à semelhança do que ocorre com o advento de uma língua, só pode ser abordada a partir de um ponto de desconhecimento.

Des mains pour parler, des yeux pour entendre: la voix et les enfants Sourds ${ }^{6}$ (Mãos para

6 Meynard (2016) grafa com maiúscula a palavra Sourds falar, olhos para ouvir: a voz e as crianças Surdas $)^{7}$ propõe-se a questionar o que é desmentido, negado, e culturalmente instituído quanto à dimensão linguageira, discursiva, a qual os Surdos podem habitar e na qual podem tomar a palavra, isto é, dimensão em que eles podem ouvir e falar, e, portanto, tal como os demais parlêtres, ${ }^{8}$ convocar pesquisas tanto no domínio da linguística quanto no da clínica psicanalítica e no das experiências educativas. Para caminhar com sua proposta, Meynard (2016) busca distinguir, na história do movimento psicanalítico, aqueles que se implicaram radicalmente com essa questão, recusando-se à confusão entre sonoro e significante, bem como propondo um "Outro texto" aos efeitos nefastos de tal "desmentido". Nesse sentido, esse autor considera Françoise Dolto e Bernard This como os dois precursores de um trabalho de abertura do inconsciente freudiano, devido a seus posicionamentos, incisivos, a favor da Língua Francesa de Sinais (LSF).

A respeito de Françoise Dolto, Meynard (2016) resgata os principais marcos históricos que testemunham sua implicação com o campo dos praticantes da Língua de Sinais Francesa (LSF) e sua insistência de que "a verdade não está do lado dos especialistas" (MEYNARD, 2016, p. 143), mas sim do lado do desejo, que é inconsciente. Trata-se de um trabalho teórico -prático constante em seu percurso, que, longe de constituir uma simples posição militante, advém dos alicerces da descoberta freudiana a respeito do que concerne, de fato, o ato de tomar a palavra, isto é, entrar na experiência de constituir-se como falante em uma língua. A partir do histórico organizado cuidadosamente

para marcar, segundo ele, uma distinção entre aqueles diagnosticados, medicalmente, como surdos e aqueles que se fazem de surdos a essa problemática.

7 No presente artigo, para todas as citações desse livro, incluindo os trechos em que ele cita outros autores, como Lacan, Françoise Dolto e Bernard This, as traduções são minhas.

8 Retomado por Meynard, "parlêtre" é um termo de Lacan para dizer que, diferente da filosofia, a psicanálise não trata do ser, mas sim do falante (parlêtre = parle + être). Daí, tem-se como elaboração básica que não existe ser senão aquele que advém pelos efeitos encarnados da linguagem. 
por Meynard (2016), os anos de 1972 e de 1981 constituem dois momentos fortes em que Dolto propõe, sólida e politicamente, a descoberta freudiana ao invés da maldade e da violência engendradas aos "fisicamente surdos" pelas tomadas de posição dos oralistas.

Em seu texto "Au jeu du désir les dés sont pipés et les cartes truqués" (No jogo do desejo os dados são viciados, e as cartas marcadas), apresentado em 22 de abril de 1972, na Sociedade Francesa de Filosofia, Dolto (1981 apud Meynard, 2016, p. 149-150) afirma:

[...] a função simbólica, específica do ser humano, permite substituir o prazer de um circuito curto do desejo, sensual, imediato, por um circuito mais longo, que mediatiza pulsões e permite retardar a obtenção do alvo primeiro, para que se obtenha um novo prazer, a descobrir.

0 circuito curto é a simbiose prolongada do filho com a mãe, e também a posição de deficiente que os especialistas de diversos campos lhe atribuem no jogo das relações com os outros. Já o circuito mais longo consiste, sobretudo, em "falar à criança", isto é, ofertar-lhe como "alternativa civilizadora" sua inserção no campo simbólico.

É justamente nesse ponto que Dolto, em abril de 1981, baseia sua carta enviada ao ministro da saúde, na qual ela reafirma e explicita sua reivindicação quanto à "necessidade incontornável" de que a língua de sinais seja proposta à criança surda, o mais cedo possível, a fim de "nutrir a função simbólica continuamente em atividade entre os humanos" (DOLTO, 2005 apud Meynard, 2016, p. 154). Também, em sua conferência, em junho desse mesmo ano, no Instituto Nacional de Surdos-Mudos de Paris (INJS), a sua tônica é a mesma, porém mais bem especificada: "Que a criança seja ouvinte ou surda, a língua de sinais precede à língua de referência, Língua de Signos ou língua oral" (DOLTO, 1989 apud MEYNARD, 2016, p. 157). Em vez do pressuposto perverso de que o gesto seja inimigo do som, Dolto parte do fundamento de que todas as crianças - não somente as fisicamente surdas - encontram-se inseridas numa "língua de signos" antes de falar a língua de referência. Em síntese, Dolto argumenta que, na vida dos humanos, uma língua intervém desde o início, pois seus gestos - como perceber ou procurar o olhar da mãe, sentir ou não sentir o corpo da mãe, chorar ou sorrir devido a uma ação do outro etc. - não podem ser tomados como necessidades senão simbólicas, ou seja, numa dimensão significante, capaz de cortar a relação dual, incestuosa, e abrir o jogo do desejo, engenhoso e inventivo (MEYNARD, 2016).

No que diz respeito a Bernard This, Meynard (2016) retoma principalmente estas duas conferências: L'envie de parler (A vontade de falar), de 1975, e La voix in utero (A voz no útero), de 1989. A primeira foi apresentada no colóquio da Association Nationale des Parents d'Enfants Déficients Auditifs (ANPEDA), realizado na esteira das leis para a integração dos "portadores de deficiência" no sistema educativo padrão e considerado por Meynard (2016) como o ponto de virada para integrar sistematicamente os chamados surdos no meio ordinário. Contrapondo-se radicalmente a esse movimento, que pode ser entendido como a passagem da proibição ao desmentido, This propõe a escuta da dimensão desejante do inconsciente e a importância da triangulação estruturante como a única possibilidade de evitar o risco de um gozo incestuoso. Ao contrário do discurso dos expertos, que querem, o mais cedo possível, diagnosticar que "uma criança seja surda", ele defende o argumento de que, incontestavelmente, ela escuta, "ela escuta, e com todo seu corpo" (THIS, 1985 apud MEYNARD, 2016, p. 135). Em síntese, ele pontua a dimensão fantasmática em que a criança poderá permanecer alienada ao desejo da mãe e convoca, portanto, a função paterna, como um terceiro elemento, capaz de descolá-la dessa posição mortífera, de puro objeto. Já em sua conferência La voix in utero, pronunciada no colóquio d'Ivry, em 1989, ele vai destacar, recorrendo ao texto de Lacan "Função e campo da fala e da linguagem em psicanálise", o efeito sujeito, que, advindo do tecido significante, movimenta o desejo in- 
consciente e sustenta uma pulsação corporal. Com esse entendimento, uma língua não pode ser considerada como uma sucessão de signos a ser aprendida, sabida e utilizada por um "sujeito"; ao contrário, ela é um encadeamento significante possível no campo da linguagem que a partir da função da fala - "não somente em seus aspectos sonoros, mas igualmente visuais, táteis, gestuais, escritos etc." (THIS, 1989 apud MEYNARD, 2016, p. 140) - é responsável pela divisão do sujeito no campo do Outro.

O desejo é o fundamento de uma formação subjetivante ou de uma prática educativa que leve em conta a dimensão subjetiva, portanto, uma educação que considere em sua base a teoria psicanalítica não pode deixar de interrogar-se a respeito das condições de fala dos educandos nela envolvidos. Meynard (2010), num outro livro seu, Soigner la surdité et faire taire les sourds: essai sur la médicalisation du Sourd et de sa parole (Curar a surdez e calar os surdos: ensaio sobre a medicalização do Surdo e de sua fala) toma por exemplo, para discutir o modo como esse fundamento é desmentido, os dispositivos de inclusão da criança surda no meio educativo ordinário, desde a sua acolhida. Ele nos mostra como "un Surdo (às vezes dois ou três) é colocado num dispositivo onde somente as línguas sonorizadas são faladas por crianças ouvintes" (MEYNARD, 2010, p. 51).

Sua questão é se nos diversos dispositivos de acolhida e de integração dessas crianças há, de fato, um lugar para a língua de sinais, uma vez que se trata de uma lógica que, ao contrário de valorizar a dimensão da diferença, põe o seu foco no déficit e na doença. Eis algumas de suas perguntas (MEYNARD, 2010, p. 55):

Existe ali um grupo de Surdos? Quantos? Existe ali profissionais falantes da língua de sinais? A LSF [Língua de Sinais Francesa], no seu dispositivo, é realmente língua de ensino-aprendizado, ou somente um complemento extra? 0 que significa colocá-la em obra para que as crianças ouvintes se familiarizem também com ela?

Se tais dispositivos respondessem afirmativamente a essas questões, muito provavel- mente estaríamos diante da coexistência e do intercâmbio das diferenças linguageiras, contexto em que a criança "Surda" poderia dizer e se dizer em LSF e, a partir dessa sua inscrição numa primeira língua, poderia também dirigirse aos outros, crianças ou adultos, inscritos primeiramente em outro domínio linguístico.

Para sintetizar o que me interessa, neste artigo, desse exemplo que escolhi colher em Meynard (2016), pode ser importante explicitar qual é mesmo o passo enfrentado por sua discussão: o de que é possível praticar e pensar uma clínica psicanalítica com os Surdos, tendo em conta que a psicanálise é a colocação em ato de um discurso profano, que, na contramão do "princípio sedutor de parecer como os outros" (saber preexistente), propõe-se a escutar e reconhecer o silêncio e o insabido como a abertura para que possa acontecer algo novo (MEYNARD, 2016, p. 204). É nesse sentido que ele retoma as elaborações de fato implicadas psicanaliticamente com as realidades humanas rejeitadas pelos ideais culturais e sociais. Não se trata de caridade, nem de altruísmo, nem de ideologia do bem. Trata-se do inconsciente, ou seja, dos efeitos de uma operação que, tomando como condição a função de corte $^{9}$ do significante, faz do vivente humano um ser que fala. Ou seja, trata-se de uma estrutura de desconhecimento, que não pode substancializar-se e, muito menos, ser tachada numa classificação, nem conforme diagnósticos médicos, nem conforme um aparelho conceitual sistematizado.

\section{Alguns desdobramentos}

\section{para pensar uma experiência educativa com Libras}

Quero começar este subitem colocando-me na mesma perspectiva dos autores em que aqui me apoiei e conclamar tanto os teóricos da educação quanto os que se encontram no chão da

9 Cortar o puro gozo do corpo a favor do desejo de um sujeito, que passa a existir por causa do simbólico. 
prática, engajados numa ação transformadora e de inclusão dos fisicamente surdos na sociedade, ao desafio de não arredar o pé dos fundamentos necessários para tal empreitada. Do mesmo modo que De Lemos (1982) e Borges (2006) alertaram os linguistas e os educadores a não serem cegos diante do que comparece, nos dados referentes à fala inicial da criança, como estranho e resistente à significação, e do mesmo modo que Meynard (2016) criticou as instituições políticas, educacionais e de saúde quanto à sua surdez à condição de falantes e de ouvintes daqueles diagnosticados como surdos, inclusive negando-lhes o acesso à língua de sinais, eu insisto, nesta parte do meu texto, para que não caiamos na armadilha, talvez até benfazeja, de uma educação surda.

Para tentar uma amarração com o que trago de axial nessa discussão, pode valer a pena, neste momento, citar algumas expressões das teorias da linguagem das quais os educadores lançam mão para embasar ou iluminar as suas práticas. Para tal, lembro-me, sobretudo, das categorias conceituais de sujeito, de objeto e de outro, que geralmente comparecem na experiência bem intricados ao papel do texto (a materialidade linguística encadeada na qual o aluno está sendo imerso) e ao do papel do professor. 0 que costumo ouvir? "Um sujeito que pensa", "um sujeito de direito", "sujeito surdo", "cultura surda", "identidade surda", "identidade bilingue", "o surdo deve adaptar-se ao mundo dos falantes", "o professor (e também a família e a escola) deve adaptar-se ao mundo dos surdos", "dificuldades psíquicas do surdo", "defasagem educacional dos surdos em relação aos ouvintes", "o surdo é uma pessoa como qualquer outra". E o que eu posso escutar disso tudo, considerando principalmente a minha enunciação neste texto? As concepções de língua e de linguagem ainda comparecem aí como secundárias e, portanto, não capazes de promover um movimento rumo a uma prática que, de fato, situe esse aprendiz na dimensão linguístico-discursiva, na qual ele possa ouvir e falar numa língua de sinais, para que, a partir daí, possa deslocar-se nas suas identificações.

De modo mais específico, quanto a uma educação com crianças que inclua os fisicamente surdos, a questão que considero principal é passar de uma concepção naturalizada de infans para a consideração de uma articulação significante primordial capaz de estruturar a fala. Conforme nos alerta Lacan (1999), trata-se de não supormos o estado de infans como "puro orgânico" ou como um vazio no sentido ontológico ou existencial, pois a questão primordial que aí encontramos é que, no campo da linguagem, devido à função da fala, estamos diante de uma estruturação em que gozo e linguagem (em sua dimensão desejante) encontram-se intrincados; em que saber sistematizado e saber inconsciente comparecem literalmente ${ }^{10}$ articulados, o que não nos permite pensar nem o puro orgânico, nem o sexual como a priori.

Portanto, para explicitar como essa estruturação ocorre, também quando se trata de falar com as mãos e ouvir com os olhos, a noção lacaniana de letra, articulada à de significante, terá que ser tomada como essencial a uma teoria da escrita. Nessa teoria, segundo Lacan (2009, p. 139), trata-se da escrita que "provê de ossos todos os gozos que, por meio do discurso, mostram abrir-se ao ser falante".

Ao lhes dar ossos, ela [a escrita] sublinha o que decerto era acessível, porém estava mascarado, ou seja, que a relação sexual falta no campo da verdade, visto que o discurso que a instaura provém apenas do semblante, por só abrir caminho para gozos que parodiam - essa é a palavra adequada - aquele que é efetivo, mas que lhe permanece alheio. (LACAN, 2009, p. 139).

Caminhando, então, para uma síntese, a primeira baliza que se faz necessária para alguns passos nessa direção é uma explicitação teórica radical dos conceitos de inconsciente e de linguagem tomados como estrutura, em contraposição a todos e quaisquer revisionismos

10 "Entre centro e ausência, entre saber e gozo, há litoral, que só vira literal quando, essa virada, vocês podem tomá-la, a mesma, a todo instante. É somente a partir daí que podem tomar-se pelo agente que a sustenta." (LACAN, 2009, p. 113). 
que, tradicionalmente, os apanham, pelo viés de um método empírico, como gênese. Vale a pena lembrar, para isso, o argumento de Althusser (1993) em seu manifesto de retorno aos fundamentos de Freud e Lacan, extremamente importante para os que pretendem situar-se no campo próprio da psicanálise, em contraposição radical aos que, mais comumente, tendem às idealizações e ao modo de resolução das vias estabelecidas, antes de Freud, pelos domínios seja da biologia ou da etologia, seja da psicologia ou da sociologia.

Assim, torna-se primordial a esta discussão - e isso porque no percurso de minhas pesquisas me senti obrigado a colocar a psicanálise no meio dos campos aqui abordados (linguística e educação) - não abrir mão do que Lacan (1999, p. 90) chamou de "o nó que une o uso do significante e aquilo que podemos chamar de uma satisfação ou um prazer". ${ }^{11}$ É aí que se situa o que se tem a desenvolver a respeito do conceito de sujeito. Freudianamente falando: um complexo de "representações", ao contrário de se fechar, não faz senão manter-se, pela via da repetição, num circuito de insistência. Trata-se de pulsão, cujo circuito marca a distinção entre a estrutura da fala e a função orgânica que ela habita. Com Lacan, podemos dizer que o inconsciente, diferentemente do que é língua para Saussure, é um saber de gozo que não se sabe por si mesmo. Ele funciona de tal modo que limita o gozo e ao mesmo tempo o causa. Recusa-o, para que ele seja atingido na escala do desejo.

\section{Caminhando para uma conclusão}

Tentei escrever este texto não só para lacanianos, mas também para linguistas e

11 Ponho em questão o verbo unir que comparece nessa tradução, pois, se se trata de união, ela é imaginária, como bem sinaliza minha discussão acima sobre a letra, que comparece num litoral, e não numa fronteira. No texto em francês, esse verbo não aparece. Lá encontramos o seguinte: "le noeud entre l'usage du signifiant et ce que nous pouvons appeler une satisfaction ou un plaisir" (LACAN, 1998b, p. 86). educadores, bem como para outros psicanalistas, freudianos. Quiçá eu tenha conseguido fazer valer esse esforço, livrando-me do hermetismo, mas, ao mesmo tempo, não caindo num reducionismo. Resta-me, no entanto, além de dizer que a densidade dos conceitos aqui trazidos poderá ser melhor elucidada em outras ocasiões e contextos, uma última investida para explanar estes dois pontos a respeito das proposicões com que me referi ao signicante, à letra e ao gozo: primeiro, quando disse significante e letra na colocação em ato de uma língua de sinais, isso implica considerar que o traço distintivo a ser apagado e encadeado - portanto, o significante que será suportado pela letra - encontra-se, materialmene, nos gestos, cujos elementos ganharão estatuto de unidades linguísticas capazes de ser articuladas, nomeadas e significadas de acordo com seus diferentes valores. Segundo, quando disse gozo foi para me referir à relação entre os objetos pulsionais e o corpo falante, e, no caso de uma língua de sinais posta em uso, é muito importante destacar, entre esses objetos, o objeto voz, que Lacan (2005, p. 279), relacionando-o ao supereu, chama de "o mais original na função do desejo", o que nos possibilita pensar que o eco da materialidade linguageira que ressoa no corpo não se encontra intrinsecamente ligado ao sonoro, mas sim a uma "voz desligada de seu suporte" (LACAN, 2005, p. 298).

Vale a pena retomar, agora, o ponto em torno do qual gira a proposta de Meynard (2016, p. 81):

[...] propor às crianças Surdas, o mais precocemente possível, a possibilidade de se exprimir na $L_{S F^{12}}$ e permitir, paralelamente, às crianças ouvintes familiarizar-se com uma tal expressão linguageira implica o reconhecimento do escutar pelos olhos e permite uma aculturação civilizadora aberta sobre o escopo simbólico do gesto humano.

Não pela via mitológica, que consistiria em "devolver a palavra" àqueles que estariam dela

12 Língua de Sinais Francesa. 
privados por causa de uma deficiência (MEYNARD, 2016, p. 91), mas sim pela via fundamental da psicanálise, ele argumenta: "os olhos são chamados a escutar a cadeia da enunciação que se desenrola e na qual os significantes, pelo jogo das diferenças, escrevem os enunciados linguísticos no que diz respeito às regras sintáticas aferentes a tais línguas" (MEYNARD, 2016, p. 106). Com base no artigo de Fontaine "Les silences de la lettre (Os silêncios da letra), ${ }^{13}$ Meynard (2016) comenta que se trata de tomar o signo gestual como um signo-significante que desencadeia um funcionamento de uma "língua de escrita" - fora de todo e qualquer fonetismo - cujo processo de leitura, por descolar o signo de suas amarras figurativas, coloca em obra uma perda de gozo para que ele possa fazer inscrição.

Em síntese: tomando em conta a descoberta freudiana do inconsciente, cujo funcionamento permite pensar um aparelho de linguagem em suas leis fundamentais (homônimo, para Freud, de um aparelho psíquico e de memória), tentei sustentar nesta discussão que a existência da língua de sinais constitui-se como ponto exemplar para estudar a elaboração lacaniana em torno de uma teoria da escrita, na qual ele sub-verte categorias conceituais já antes consagradas tanto pela linguística (signo, significante, significado e língua) quanto pela psicanálise freudiana (pulsão e objetos pulsionais, entre outros). A partir desse percurso, busquei situar a experiência educativa com os falantes de Libras no campo dos estudos que buscam articular linguagem, psicanálise e educação. Deixo, por fim, aos estudiosos e profissionais da educação, das letras, e das ciências humanas em geral, os resultados a que pude chegar com as minhas pesquisas, até esse momento, como uma provocação, a meu ver, ainda subversiva, mesmo estando nós no século XXI.

13 Meynard considera esse artigo de Fontaine como precursor, realçando, sobretudo, que ele, a partir de uma leitura dO seminário, livro 9: A identificação, de Lacan, introduz questões essenciais relativas a uma clínica com falantes de línguas de sinais (MEYNARD, 2016).

\section{Referências}

ALTHUSSER, L. Écrits sur la psychanalyse: Freud et Lacan. Paris: STOCK/IMEC, 1993.

BORGES, S. o quebra-cabeça: a alfabetização depois de Lacan. Goiânia: Editora da Pontifícia Universidade Católica de Goiás, 2006.

BURGARELLI, C. G. A subversão do sujeito: em vez de cogito, desejo. In: CONGRESSO INTERNACIONAL TRANSDISCIPLINAR SOBRE A CRIANÇA E O ADOLESCENTE, 6., 2020, São Paulo. Simpósio: Saber, desejo e conhecimento - Piaget, Freud e Lacan. Anais eletrônicos [...]. São Paulo: Instituto Langage, 2020. (Realizado on-line).

DE LEMOS, C. T. G. Sobre a aquisição de linguagem e seu dilema (pecado) original. Abralim, Recife, Boletim 3, p. 97-126, 1982. Disponível em: https://www.abralin.org/site/wp-content/ uploads/2018/12/boletim3a.pdf. Acesso em: 21 jul. 2020.

De LEMOS, C. T. G. Los processos metafóricos e metonímicos como mecanismos de cambio. Substratum, Barcelona, v. 1, n. 1, p. 121-135, 1992.

FREUD, S. Carta 52. In: FREUD, S. Edição Standard Brasileira das obras psicológicas completas de Sigmund Freud, vol. I. Rio de Janeiro: Imago, 1977. p. 317-324.

LACAN, J. A instância da letra no inconsciente ou a razão desde Freud. In: LACAN, J. Escritos. Rio de Janeiro: Jorge Zahar, 1998a. p. 496-536.

LACAN, J. Le séminaire, livre V: les formations de l'inconscient. Paris: Seuil, 1998b.

LACAN, J. 0 seminário, livro 5: as formações do inconsciente. Rio de Janeiro: Jorge Zahar, 1999.

LACAN, J. 0 seminário, livro 10: a angústia. Rio de Janeiro: Jorge Zahar, 2005.

LACAN, J. Lição sobre Lituraterra. In: LACAN, J. 0 seminário, livro 18: de um discurso que não fosse semblante. Rio de Janeiro: Jorge Zahar, 2009. p. 105-119.

LACAN, J. Le séminaire, livre IX: l'identification. Inédito. Disponível em: http://staferla.free.fr/S9/ S9.htm. Acesso em: 15 jul. 2020.

LE GAUFEY, G. A inconsistência do simbólico: de René Descartes a Jacques Lacan. Tradução de Paulo Sérgio de Souza Jr. Campinas, SP: Editora da Unicamp, 2018.

MEYNARD, A. Des mains pour parler, des yeux 
pour entendre: la voix et les enfants Sourds. Toulouse: Érès, 2016.

MEYNARD, A. Soigner la surdité et faire taire les Sourds: essai sur la médicalisation du Sourd et de sa parole. Toulouse: Érès, 2010.

MILNER, J-C. 0 amor da língua. Tradução de Paulo César de Souza Jr. Campinas, SP: Editora da Unicamp, 2012.

MORAES, M. R. S. Materna/estrangeira: o que Freud fez da língua. 1999.145 f. Tese (Doutorado em Linguística) - Instituto de Estudos da Linguagem, Universidade Estadual de Campinas (UNICAMP), Campinas, SP, 1999.

MOTA, S. B. V. 0 quebra-cabeça da escrita: a instância da letra na aquisição da escrita. 1995. 271 f. Tese (Doutorado em Psicologia da Educação) Programa de Estudos Pós-graduados em Educação, Pontifícia Universidade Católica de São Paulo (PUCSP), São Paulo, 1995.

MUSSALIM, F.; BENTES, A. C. (org.). Introdução à linguística: domínios e fronteiras. Vol. 1. São Paulo: Cortez, 2001a.
MUSSALIM, F.; BENTES, A. C. (org.). Introdução à linguística: domínios e fronteiras. Vol. 2. São Paulo: Cortez, 2001b.

MUSSALIM, F.; BENTES, A. C. (org.). Introdução à linguística: fundamentos epistemológicos. Vol. 3. 5. ed. São Paulo: Cortez, 2011.

SAUSSURE, F. Curso de linguística geral. Tradução de Antônio Chelini, José Paulo Paes e Izidoro Blikstein. 9. ed. São Paulo: Cultrix, 2006.

UNIVERSIDADE FEDERAL DE GOIÁS. Faculdade de Educação. Projeto pedagógico: curso de Pedagogia. 2015. Disponível em: https://files.cercomp. ufg.br/weby/up/2/o/2018PPC_Pedagogia_(1). pdf?1518023839. Acesso em: 20 jul. 2020.

WEEDWOOD, B. História concisa da linguística. Tradução de Marcos Bagno. São Paulo: Parábola, 2012.

Recebido em : 25/07/2020

Revisado em : 09/12/2020

Aprovado em : 11/12/2020 